06.2

\title{
Динамическое рассеяние света в жидкокристаллических ячейках с микроструктурами металл-диэлектрик-полупроводник, содержащими золотые наночастицы
}

\author{
(С) Д.П. Щербинин, Л.П. Амосова, А.Е. Большакова, Е.А. Коншина \\ Санкт-Петербургский национальный исследовательский университет информационных технологий, механики и оптики \\ (Университет ИТМО), Санкт-Петербург, Россия \\ E-mail: shcherbinin.dmitrij@gmail.com
}

Поступило в Редакцию 2 апреля 2019г.

В окончательной редакции 2 апреля 2019г.

Принято к публикации 4 апреля 2019г.

\begin{abstract}
Показана возможность снижения порога эффекта динамического рассеяния света в жидкокристаллических ячейках. Снижению порога способствует использование электродов с микроструктурами металл-диэлектрик-полупроводник, содержащими золотые наночастицы. Повышение эффективности электродов приводит к увеличению проводимости ячеек и ослаблению интенсивности света в области низких напряжений.
\end{abstract}

Ключевые слова: жидкие кристаллы, динамическое рассеяние света, золотые наночастицы.

DOI: 10.21883/PJTF.2019.13.47949.17821

Поиск способов управления ослаблением оптического излучения в широкой области спектра с высоким контрастом, быстродействием и поляризационной независимостью является актуальной проблемой современных фотонных устройств. Эффект динамического рассеяния света (ДРС) в жидких кристаллах (ЖК, LC) позволяет управлять ослаблением света в видимой и ИК-областях спектра [1-5].

Существенно возросший в последние годы интерес к исследованиям динамического рассеяния света связан c перспективностью его применения. Была показана возможность ослабления интенсивности света до пяти порядков, правда при очень высоких напряжениях и на довольно большом расстоянии $(1 \mathrm{~m})$ от рассеивающей плоскости [1]. Достигнуты малые времена оптической релаксации - до $22.5 \mathrm{~ms}$ для массивов тонких светорассеивающих ЖК-ячеек [2]. Показано влияние параметров электрического поля на времена переключения в рассеивающих ячейках [3]. Продемонстрирована возможность селективной аттенюации в рассеивающих ячейках в видимой и ИК-областях спектра [4]. Исследуются альтернативные подходы, в том числе светоуправляемые гидродинамические нестабильности в ЖК [6].

Преимуществом эффекта ДРС по сравнению с ориентационным эффектом Фредерикса является его поляризационная независимость. Необходимость использования поляризаторов усложняет оптические схемы и приводит к существенным потерям световой интенсивности (до 50\% на каждом поляризаторе). ДРС в нематическом жидком кристалле вызвано электрогидродинамической неустойчивостью, возникающей в результате противодействия процессов переориентации директора и протекания ионного тока при приложении напряжения к ЖК-ячейке [1-5].
Основной недостаток ЖК-структур, работающих в режиме динамического рассеяния, - высокие рабочие напряжения. Снижение рабочих напряжений сделает такие поляризационно-независимые ограничители излучения значительно более конкурентоспособными.

Давно известны типы ненакаливаемых катодов на основе автоэлектронной эмиссии из структур металл-диэлектрик-металл (вариант: хорошо проводящий полупроводник-диэлектрик-металл) и из гранулированных пленок металлов на диэлектрической подложке. Известно, что нанокристаллы любого вещества обладают меньшей работой выхода, чем массивные образцы того же вещества. Это происходит из-за того, что горячие электроны с энергией больше работы выхода не теряют ее в результате рассеяния на фононах, так как фононный спектр в наночастицах дискретен и фононы с „необходимой для рассеяния электрона“ энергией в нем в большинстве случаев отсутствуют. В то же время встает проблема доставки электронов в наночастицы металла. Традиционно таким источником является поперечное по отношению к тянущему электрическое поле. Пленка наносится между двумя заранее созданными электродами. В этом случае через пленку при определенных напряжениях начинает течь туннельный ток. Совместив эти две структуры, получим катод, в котором на проводящий электрод (например, оксид индия-олова, ITO) напыляется достаточно тонкая (до $50 \mathrm{~nm}$ ) сплошная пленка диэлектрика (например, кварца), поверх которой наносится гранулированная пленка золота. В итоге получается матрица микродиодов Шоттки [7]. Подобные структуры можно использовать в качестве одного из электродов ЖК-ячейки, работающей на основе эффекта динамического рассеяния. 


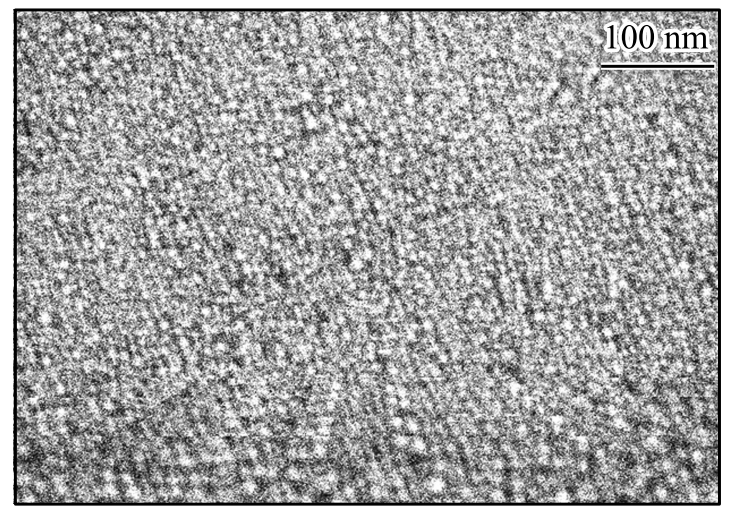

Рис. 1. СЭМ-изображение золотой островковой пленки.

Оптический порог ЖК-ячеек в режиме динамического рассеяния света

\begin{tabular}{c|c|c}
\hline Номер ячейки & Структура ячейки & $\begin{array}{c}\text { Оптический } \\
\text { порог, V }\end{array}$ \\
\hline 1 (контрольная) & $\mathrm{ITO} / \mathrm{SiO}_{2} / \mathrm{LC} / \mathrm{Chr} / \mathrm{ITO}$ & 4 \\
2 & $\mathrm{ITO} / \mathrm{SiO}_{2} / \mathrm{Au} / \mathrm{LC} / \mathrm{Chr} / \mathrm{ITO}$ & 0 \\
3 & $\mathrm{ITO} / \mathrm{SiO}_{2} / \mathrm{Au} / \mathrm{LC} / \mathrm{ITO}$ & 0
\end{tabular}

В настоящей работе исследованы зависимости пропускания и проводимости от напряжения ЖК-ячеек, содержащих структуры металл-диэлектрик-полупроводник (МДП), с использованием гранулированных золотых пленок на межфазной границе с целью получения ослабления пропускания при низких напряжениях.

Для проведения исследований использовался нематический жидкий кристалл ЖК-440 (НИОПИК, Москва) с отрицательной диэлектрической анизотропией $\Delta \varepsilon=-0.4$ и анизотропией электропроводности $\Delta \sigma=+1.55$. Плоскопараллельные ячейки собирались из стеклянных подложек, покрытых прозрачными проводящими слоями ITO. В качестве контрольной ячейки использовалась гибридно-ориентированная ячейка № 1 (см. таблицу). Параллельная ориентация ЖК-молекул на одной из подложек задавалась с помощью поликристаллической пленки $\mathrm{SiO}_{2}, \quad$ а вертикальная ориентация на противоположной подложке - слоем хромолана $(\mathrm{Chr})$. $\mathrm{B}$ ячейках № 2 и 3 на слой $\mathrm{SiO}_{2}$ осаждалась золотая гранулированная пленка. Эти ячейки различались тем, что у ячейки № 2 противоположный электрод был покрыт ориентирующим слоем хромолана, а у ячейки № 3 ориентирующий слой отсутствовал (см. таблицу). Толщина ячеек, заданная с помощью тефлоновых прокладок, контролировалась емкостным методом и составляла $18 \pm 1 \mu \mathrm{m}$.

Слои ITO наносились на подложки путем катодного распыления в аргоновой плазме с последующим отжигом слоев на воздухе при температуре $450^{\circ} \mathrm{C}$. Удельное сопротивление слоев ITO (около $200 \Omega / \square$ ) было значительно меньше сопротивления ЖК, что позволяло не учитывать его при проведении измерений и анализе данных. Ориентирующие слои хромолана осаждались центрифугированием его раствора в изопропиловом спирте с помощью спин-коатера APT Spin-150i NPP. После осаждения эти слои подвергались термообработке в течение часа при температуре $120^{\circ} \mathrm{C}$. Тонкие пленки диоксида кремния получались путем лазерного распыления кварцевой мишени в вакуумной установке „ФерриВатт“. Гранулированная золотая пленка наносилась термическим распылением в вакууме на установке Kurt Lesker, а затем отжигалась при $200^{\circ} \mathrm{C}$. Изображение структуры гранулированной золотой пленки, полученное с помощью сканирующего электронного микроскопа $(\mathrm{CЭM})$, показано на рис. 1. Она состоит из плотноупакованных золотых наночастиц диаметром порядка $10 \mathrm{~nm}$.

Зависимости ослабления пропускания от напряжения в видимой области спектра измерялись на спектро-

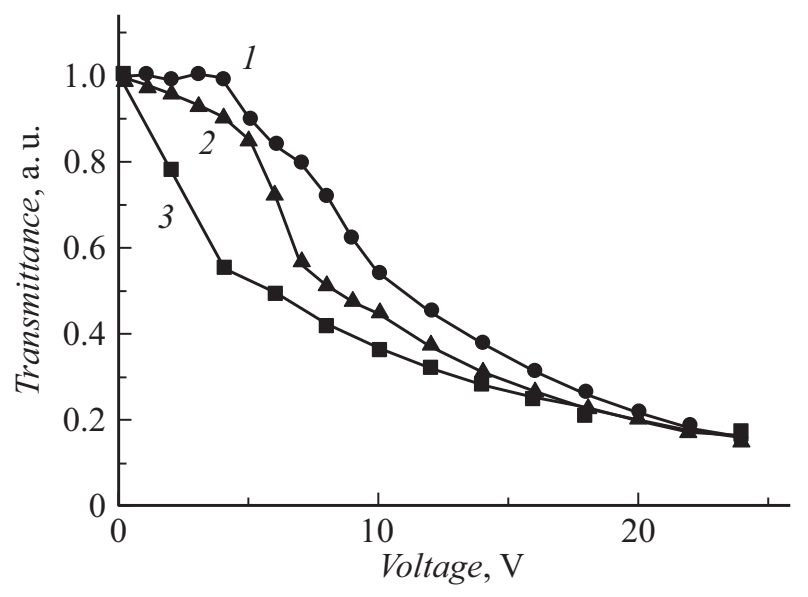

Рис. 2. Зависимость пропускания ЖК-ячеек от напряжения в режиме динамического рассеяния света. 1 - контрольная ячейка, $2-\mathrm{ITO} / \mathrm{SiO}_{2} / \mathrm{Au} / \mathrm{LC} / \mathrm{Chr} / \mathrm{ITO}$, $3-\mathrm{ITO} / \mathrm{SiO}_{2} / \mathrm{Au} / \mathrm{LC} / \mathrm{ITO}$.

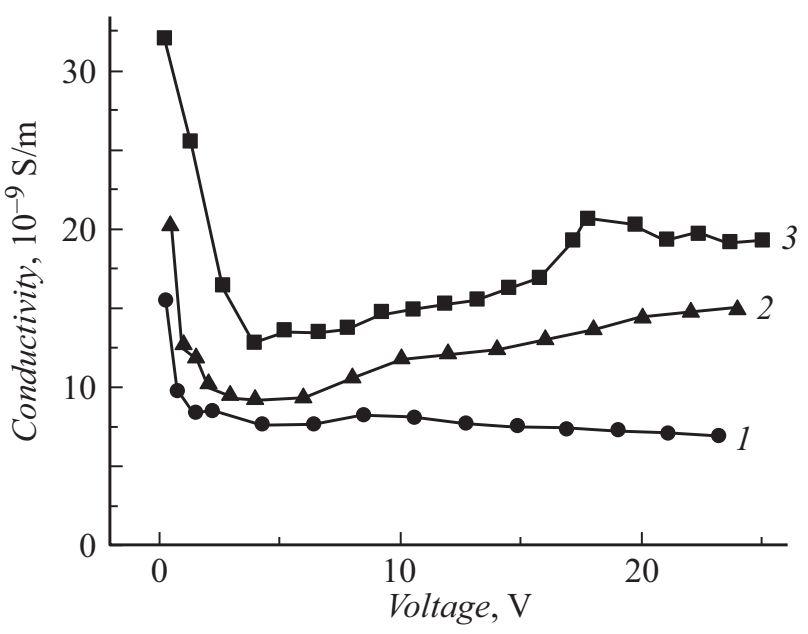

Рис. 3. Зависимость проводимости ЖК-ячеек от напряжения. $1-$ контрольная ячейка, $2-\mathrm{ITO} / \mathrm{SiO}_{2} / \mathrm{Au} / \mathrm{LC} / \mathrm{Chr} / \mathrm{ITO}$, $3-\mathrm{ITO} / \mathrm{SiO}_{2} / \mathrm{Au} / \mathrm{LC} / \mathrm{ITO}$. 
фотометре СФ-56 (ЛОМО, Санкт-Петербург, Россия). Расстояние между плоскостью образца и фотодетектором составляло $20 \mathrm{~cm}$. К ЖК-ячейкам прикладывалось постоянное напряжение. Для измерения проводимости ЖК-ячеек и контроля их толщины использовался прецизионный измеритель импеданса Agilent E4980A (Keysight Technologies, CША).

На рис. 2 приведены зависимости пропускания ЖК-ячеек от постоянного напряжения. На электрод с золотыми наночастицами подавался „минус“, т.е. он являлся катодом. В отличие от ячейки № 1 в ЖК-ячейках № 2 и 3 с золотыми наночастицами на межфазной границе наблюдался спад пропускания с увеличением приложенного напряжения без явно выраженного порога. Это можно объяснить увеличением стационарной проводимости ЖК-ячеек.

На рис. 3 приведены зависимости проводимости ЖК, рассчитанные из вольт-амперных характеристик исследуемых ячеек. У ЖК-ячейки № 3 с резким спадом пропускания в области напряжений до $5 \mathrm{~V}$ (рис. 2) проводимость была практически в 2 раза больше, чем у контрольной ячейки № 1 . Это свидетельствует о том, что при использовании МДП-структуры $\mathrm{Au} / \mathrm{SiO}_{2} / \mathrm{ITO}$ в качестве катода проводимость ЖК-ячейки увеличивается за счет снижения работы выхода из наночастиц $\mathrm{Au}$ на поверхности электрода и дополнительной эмиссии электронов. Носители заряда туннелируют от полупроводникового электрода ITO к Au-наночастицам через слой $\mathrm{SiO}_{2}$ с последующей инжекцией в ЖК-среду. Для нематических ЖК характерна ионная проводимость, поэтому инжектируемые электроны приводят к ионизации ЖК-среды. Экстракция зарядов из ЖК происходит на противоположном инжектирующем электроде (аноде). Слой хромолана на электроде в ЖК-ячейке № 2 приводил к понижению проводимости, затрудняя процесс экстракции зарядов (рис. 3). В отсутствие слоя хромолана в ЖК-ячейке № 3 ее проводимость существенно увеличивалась благодаря стеканию зарядов с электрода. Подтверждением инжекции электронов в ЖК в присутствии $\mathrm{Au}$-наночастиц на межфазной границе является тот факт, что при смене полярности наблюдалось существенное уменьшение проводимости и, как следствие, увеличение пропускания ячейки (просветления) [8].

Для дальнейшего усиления интенсивности рассеяния при малых напряжениях проводимость ЖК должна быть существенно выше. Возникновение вращающих моментов для ЖК-молекул происходит при определенной силе ионных токов. Отсюда и нижний предел проводимости ЖК, при котором возникает рассеяние. Если мы понижаем рабочее напряжение в $n$ раз, то для сохранения той же силы тока, согласно закону Ома, мы должны во столько же раз увеличить концентрацию исходных примесей в ЖК. Выбор химической природы допирующего вещества и расчет его необходимой концентрации с целью усиления эффективности рассеяния в области низких напряжений могут служить предметом дальнейших научных исследований в данном направлении.
Результаты исследований ЖК-ячеек с гранулированными золотыми пленками на межфазной границе показали возможность снижения рабочих напряжений для эффекта динамического рассеяния света в ЖК. Использование матрицы МДП-диодов $\mathrm{ITO} / \mathrm{SiO}_{2} / \mathrm{Au}$ на одной из подложек ЖК-ячейки (катоде) способствовало ослаблению пропускания в результате электрогидродинамической неустойчивости практически без порога при низких напряжениях постоянного поля.

\section{Конфликт интересов}

Авторы заявляют, что у них нет конфликта интересов.

\section{Список литературы}

[1] Geis M.W., Bos P.J., Liberman V., Rothschild M. // Opt. Express. 2016. V. 24. N 13. P. 3812-13823. DOI: $10.1364 / \mathrm{OE} .24 .013812$

[2] Serak S.V., Hrozhyk U., Hwang J., Tabiryan N.V., Steeves D., Kimball B.R. // Appl. Opt. 2016. V. 55. N 30. P. 8506-8512. DOI: $10.1364 / A O .55 .008506$

[3] Konshina E.A., Shcherbinin D.P. // Liq. Cryst. 2018. V. 45. N 2. P. 292-302. DOI: 10.1080/02678292.2017.1323353

[4] Chiang S.P., Wang C.T., Feng T.M., Li C.C., Jau H.C., Su S.Y., Yang S.D., Lin T.H. // Opt. Express. 2018. V. 26. N 13. P. 17009-17014. DOI: $10.1364 /$ OE.26.017009

[5] Пожидаев Е.П., Мудрещов Д.А., Шошин В.М., Бобылев Ю.П., Жуков А.А., Веселаго В.Г. // Письма в ЖТФ. 2013. T. 39. B. 11. C. $45-51$.

[6] Zhan Y., Schenning A.P., Broer D.J., Zhou G., Liu D. // Adv. Funct. Mater. 2018. V. 28. N 21. P. 1707436 (1-7).

DOI: $10.1002 /$ adfm. 201707436

[7] Елинсон М.И. Ненакаливаемые катоды. М.: Сов. радио, 1974. $336 \mathrm{c}$.

[8] Амосова Л.П., Бойков Д.С., Щербинин Д.П. // ЖТФ. 2017. T. 87. B. 9. C. $1376-1383$. 